\title{
ISO 14000 and Its Perceived Impact on Corporate Performance
}

\author{
Maruf Hasan (Corresonding author) and Chun Kit Chan \\ School of Mechanical \& Manufacturing Engineering \\ The University of New South Wales, Sydney 2052, Australia \\ Tel: 61-2-9385-5692Ｅ-mail: m.hasan@unsw.edu.au
}

Received: August 8, 2014 Accepted: October 16, 2014 Published: November 3, 2014

doi:10.5296/bmh.v2i2.6546ＵRL: http://dx.doi.org/10.5296/bmh.v2i2.6546

\begin{abstract}
ISO14000 is an international environmental standard that acts as a guideline for companies to improve its performance in environmental aspects. Researches related to ISO14000 shows that the implementation has not only improved companies' environmental performance, but this has also enhanced companies' corporate performance. In this research, a project is carried out to determine the benefits and costs of ISO14000, which necessitates the inspections of companies' performance in corporate and environmental aspects. A questionnaire survey was carried out to achieve this and s the results from the survey shows that ISO14000 had an excellent performance in environmental aspects such as reducing waste and usage of materials and energy. In the business aspects, however, the performances were average due to high time expense for this system maintenance and cost of certification and surveillance.
\end{abstract}




\section{Introduction}

Nowadays, the issues due to environments such as lack of raw materials and world pollution have become increasingly serious and raise the concerns of government, non-governments organization, public, companies and communities. Therefore, numerous plans that involve environmental protection and sustainability have been more regarded, such as implementation of ISO standards.

ISO14000 family chiefly focuses on environmental management and assists organization in reducing harmful effects to the environment produced by its activities as well as constantly achieving enhancement of its environmental performance (ISO,2008). These standards are considered as process standards and not performance standards. By implementation of this system, organizations will not be precisely told the outcome of its environmental performance but instead, the ISO14000 standards serve as a guidelines for organizations to follow (Tibor and Feldman, 1996). According to Cascio (1996), the series of ISO14000 were created in close proximity by fifty countries over a five-year period and were made public in July, 1996 (Tabor et al., 1996). Since diverse sets of environmental standards have been continuously proliferating globally, it was necessary for the ISO technical committee to progress and improve its set of ISO14000 standards (Tibor and Feldman, 1996). ISO14000 represents a generic portrayal for the 20 specific global environmental management standards and guidelines (Hersey, 1998).

Within the series of ISO14000 standards, the ISO14001 standard (Environmental Management System - Specification with Guidance for use) is considered to be most significant (Boiral and Sala, 1998).

ISO14001 is a new international standard for EMS. It provides the framework for the management system to improve the corporate and environmental performance. According to Sroufe, (Sroufe et al., 2000), an EMS consists of formal systems and databases and is then followed by an integration of procedures and processes. As a result, it will aid the training of personnel, monitoring, summarizing and reporting of specialized environmental performance information to both the internal and external stakeholders of an organization.

The documentation of the 'environmental performance' information predominantly focuses on internal management in terms of design, pollution control and waste minimization, training, reporting to top management, and the setting of goals. Moreover, this information will be documented in its annual reports, which focuses on the organisations' outputs as well as to boost its overall image (Sroufe et al., 2000)

In addition, the ISO14001 standard specify requirements for the establishment of environmental policy, determination of environmental aspects and impacts of products and/or services, planning environmental objectives and measurable targets, implementation and operation of programs to meet objectives and targets, corrective action, and management review (Tibor and Feldman, 1996).

The ISO14001 standard serves as an assistant for companies during its' environmental performance and operation inspections. It is required by ISO140001 that a company ought to 
develop an environmental policy, sets of objectives in order to meet the environmental policy, monitor progression towards objectives, alleviate environmental problems and constantly revising the EMS in order to ensure continual improvement of environmental performance (Johannson, 1993: Kirkpstrick and Pouliot, 1996; Kitazawa and Sarkis, 2000).

Nowadays, the world is facing the increasing lack of raw materials and the serious issue to world pollution. Thus, it is crucial to consider the implementation of ISO14001 standard. Johnson (1997) has laid emphasis that ISO14001 was not simply another plan, but instead, it was part of the way we all live. The implementation of ISO14001 has been gradually increasing globally. In December 2003, the number of worldwide organization that had implemented ISO14001 had exceeded 66,000 (Barla, 2007). In January 2007, it has evidently shown that the total number of ISO14001 certification worldwide had reached 129,031. The average number of organization implementing ISO 14001 is roughly 21,333 per year across the world.

\section{Objective}

In this research paper, the objective focuses on the impact of the ISO14000 standards on corporate performance. This includes discussion of the positive and negative impacts to the organization certified by ISO 14000, where the organizations are mainly in Australia. In addition, the corporate performance of the organizations which are certified by ISO14000 will be compared to organizations without certification by ISO14000.

\section{Literature Review}

Why ISO14001 is necessary; There are three main reasons for the necessity for ISO14001 standard implementation, which are the environmental, market or business and pressure aspects. Worldwide population has been continuously increasing year by year as well as the rapid increase of raw material, resource and energy consumption. Raw material, useful resources and energy are limited. All of these resources will eventually be completely used up in the future years (Miller, 1996). As a result, the environmental sustainability will become a main solution to protect the environment and human life. Therefore, the ISO14001 standard acts as a tool for company's constant improvements to meet the aim of sustainability (Chen, 2005; Macdonald, 2005). Another concern due to increasing population is pollution in the environment. Pollution, which includes air pollution and water pollution, has become a serious issue as both will cause potential harm to the environment. Implementation of ISO14001 standard is an opportunity for companies to improve their performance in environmental sustainability and minimize pollution in the environment. It is necessary for companies in order to improve its environmental aspects.

Market or Business Aspect: There is a growing amount of customers and companies worldwide that are concerned of the environmental issues. Hence, many companies focus towards the environmental aspects in order to gain more support from its customers as they have a propensity to buy environmental products (Davis, 1991). Moreover, due to the increasing concept and thinking of environmental protection, the relationship between a company and its stakeholders, which includes employees, suppliers, competitors, community, 
government agencies, and non-government organizations has been improved (Boiral and Sala, 1998). The implementation of the ISO14001 standard has also helped companies to portray an environmentally friendly image (Pouliot, 1991). ISO14001 has become an "international passport”(Tibor and Feldman, 1996) and dominant tendency (Rothery, 1995) for companies to sell their products or services to other countries.

Pressure Aspects: The four main pressures, which forces companies to implement ISO14001 standards to become environmentally friendly, are market pressure, social pressure, financial pressure and regulatory pressure (Bansal and Roth, 2000; Bansal and Howard, 1997). Market pressure comes from the competition with other companies, suppliers and customers. Social pressure, on the other hand, comes from the general pubic, various communities and the environmental organization. Financial pressure, as self stated, comes from insurance companies and financial institutions. Finally, regulatory pressure comes from the government and international regulations (Berry and Rondinelli, 1998: Fineman and Clarke, 1996). In today's world, many suppliers are forced to implement ISO14001 in order to gain an opportunity to combine forces or collaborate with the organizations (Shin and Chen, 2000). According to Boiral and Sala (1998), it is required by the ISO14000 standards that "companies are not only to adopt an EMS, but to ensure their suppliers do so as well". Therefore, the implementation of ISO14001 standard becomes a key for organizations to select their suppliers (Clark, 1999).

Benefits in Environment: The implementation of ISO14000 brings plenty of benefits in environmental aspects. Firstly it is mentioned that adoption of the ISO14000 can reduce waste. ISO14000 can also help in saving material by re-using and recycling materials (Jump, 1995). Secondly, ISO14000 helps to improve the environmental performance and continues to develop new products to improve the environment. Resultantly, the companies have the ability to redesign product such that environmental issue is eliminated during product usage or disposal (Sayre, 1996; Zuckerman, 1997). In addition, ISO14000 can improve companies to pay more attention to environmental responsibility in order to provide consciousness of environmental to the employees (Sayre, 1996).

Benefits in Business: The benefits of ISO140001 in businesses are more than they are in environmental aspects. Firstly, ISO14001 helps the companies to enter the international market. Secondly, market share has been increased by the implementation of ISO14000 (Walker, 2000). Suppliers have been asked to meet the specific environmental requirements, such as ISO14001 by companies. Therefore, the opportunity to work in partnership with other companies has been increased through the implementation of ISO14000.

Besides, the awareness of environment for employees has been increased by the implementation of ISO14001 (Sayre, 1996). The morale of employees has been improved where they will pay more attention to the environmental aspects. Furthermore, qualities of products have been enhanced to meet the requirement of customers, due to the improvement of operations in companies (Holt, 1998). Moreover, the cost of material can also be reduced due to improvement of company operations (Holt, 1998), the increased efficiency of the process and more material as been re-used or recycled (Jump, 1995). Additionally, external 
recognition and assurance of conformity may be obtained when a company with ISO14001 certification verifies with a third party. The certification of ISO14001 can be audited by an accredited third party. (Barla,2007). Implementation of ISO14000 can have a better relationship between company, stakeholders and other investors (Coulson, 1999). The adoption of ISO14000 standards acts as a company strategy for marketing, which will enhance the relationship between the company and its stakeholders (Polonsky, 1995).

Shortcomings of ISO14001: Although ISO 14001 is a standard for improving the environmental performance, it is only a process standard and not a performance standard. Hence, it is not guaranteed to a company a definite level of improvement in environmental performance and what level of environmental performance will be reached (Tibor and Feldman, 1996).

Impediments of ISO14001: The obstacles for companies to implement ISO14001 can be split into internal and external barriers. According to Hillary (2004), internal barriers can be divided into resources, understanding and perception, implementation and attitudes and company culture. Moreover, external barriers can be divided into certification, economics, institutional weaknesses and support and guidance (Hillary, 2004). In addition, cost is one of the impediments for company to implement ISO14001. The relevant costs are training cost, consultation cost, the process cost, registration cost and maintenance cost.

\section{Methodology}

A questionnaire survey was used to inspect the benefit and cost of ISO14000. The number of questions in the survey was approximately 22. The survey involved open ended questions, yes/no questions and rating questions. The survey was partly based on a previous similar survey (Montabon et al., 2000). A total of 850 surveys had been sent out to companies which had implemented ISO14001 and 240 surveys had been sent to companies which were not certified by ISO14000. There were a total of 222 surveys returned back. Of these 17 surveys were incomplete. Therefore, only 205 (24\%) surveys were valid. Within the 205 surveys, 170 surveys came from companies which had implemented ISO14001 and 35 surveys were returned by non-ISO14000 implemented companies. Within the ISO14000 certification companies, 2 groups were separated: the manufacturing group and the non-manufacturing group. The manufacturing group included all companies related to production and construction, with a total of 125 surveys (73.5\% out of 170 surveys). The non-manufacturing group included all companies that provided services, distributions, management, business etc., with a total of 45 surveys (26.5\% out of 170 surveys). The non-ISO14000 certified companies only consisted of companies related to manufacturing hence they were compared with manufacturing companies that were certified by ISO14000. Due to space limitation, only the details of ISO14000 certified manufacturing companies are reported below. A comparison of the analysis of manufacturing and non-manufacturing companies and also ISO14000 certified and non-ISO14000 certified companies will be briefly presented in the discussion later. 


\section{1) Macrothink}

\section{Analysis and Discussion}

Surveys were randomly sent out to companies and results revealed that small and medium sized companies accounted for a total of 91\%. Response to selected survey questions (5-13 ) are provided in Table 1.

Table 1. Response to selected survey questions

\begin{tabular}{|c|c|c|c|c|c|c|}
\hline Item & $\begin{array}{l}\text { Strongly } \\
\text { Disagree } \\
(\%)\end{array}$ & Disagree(\%) & $\begin{array}{l}\text { Normal } \\
(\%)\end{array}$ & Agree(\%) & $\begin{array}{l}\text { Strongly } \\
\text { Agree(\%) }\end{array}$ & Mean \\
\hline $\begin{array}{l}\text { Q5 Negative impact of your company } \\
\text { in the market }\end{array}$ & 54 & 31 & 15 & 0 & 0 & 1.612 \\
\hline $\begin{array}{l}\text { Q6 The quality of products has met } \\
\text { customer expectation. }\end{array}$ & 7 & 3 & 13 & 41 & 36 & 3.974 \\
\hline $\begin{array}{l}\text { Q7 Continue to investigate new } \\
\text { procedures to improve your comapny }\end{array}$ & 5 & 6 & 8 & 40 & 41 & 4.055 \\
\hline $\begin{array}{l}\text { Q8 The reputation of your company } \\
\text { has increased }\end{array}$ & 4 & 11 & 22 & 38 & 25 & 3.686 \\
\hline $\begin{array}{l}\text { Q9 Most of your waste from the } \\
\text { production process has reduced }\end{array}$ & 2 & 14 & 28 & 33 & 23 & 3.617 \\
\hline $\begin{array}{l}\text { Q10 Overall, there is an increase of } \\
\text { company's profit compared to without } \\
\text { implementation of ISO14000 }\end{array}$ & 6 & 25 & 46 & 16 & 7 & 2.910 \\
\hline $\begin{array}{l}\text { Q11 In the international market, the } \\
\text { sales of sthe product has increased. }\end{array}$ & 17 & 14 & 44 & 19 & 6 & 2.833 \\
\hline $\begin{array}{l}\text { Q12 Better production process leads to } \\
\text { better outcome }\end{array}$ & 3 & 8 & 13 & 50 & 26 & 3.851 \\
\hline $\begin{array}{l}\text { Q13 Market share of your company has } \\
\text { increased }\end{array}$ & 8 & 12 & 43 & 33 & 4 & 3.124 \\
\hline $\begin{array}{l}\text { Q14 The overall costs (such as } \\
\text { production and management) has } \\
\text { reduced }\end{array}$ & 6 & 31 & 33 & 24 & 6 & 2.918 \\
\hline $\begin{array}{l}\text { Q15 Quality of the product has } \\
\text { increased }\end{array}$ & 3 & 16 & 30 & 44 & 7 & 3.355 \\
\hline Q16 Leadtimes can be reduced & 5 & 20 & 48 & 24 & 3 & 2.988 \\
\hline $\begin{array}{l}\text { Q17 Your company got certified to } \\
\text { ISO14000 because of pressure from } \\
\text { customers and suppliers }\end{array}$ & 18 & 20 & 20 & 20 & 22 & 3 \\
\hline
\end{tabular}

Response to Q5 shows that no companies considered the ISO14000 standard to bring negative impact, and more than $80 \%$ of the companies state that ISO14000 gave a positive 
impact of company position in the market. A positive impact of company position in market may improve the relationship between the companies and stakeholder (Polonsky, 1995). Therefore, the investment from the stakeholder to the company may increase, which may lead the company to increase its profit and its occupational activities. For Q7, 41\% companies agreed and 40\% strongly agreed that the ISO14000 standard would help to continue investigating new procedures to improve the company's performance. By improving the company's performance, it may lead to enhanced quality of products to meet customer' expectation (Holt, 1998; Sroufe et al., 2000). This matches the results with Q12, where 50\% companies agreed and 26\% companies strongly agreed (mean 3.851) that ISO14000 had helped to improve the outcome by a better production process. The better the production process, the increased quality of product it brings. Q15 indicates that $44 \%$ companies agreed and 7\% companies strongly agreed (mean 3.355) that the quality of their product had increased. This also matches the result with response to Q6, where $41 \%$ companies agree and $36 \%$ strongly agreed (mean 3.974) that customers' expectation had been met by the product's quality. As a result, companies will not lose its customers as customers' requirements have been satisfied. The implementation of ISO14000 can help the company to meet customer's requirements, and thereby this can improve the relationship between customers and companies. Moreover, due to the increased quality of products and companies becoming more considerate and are aware of the environment, customers have the tendency to buy environmental products (Davis, 1991). In Q8. 15\% of all companies indicated hat the company's reputation had not increased even though ISO14000 was implemented. This may be due to celebrity rating of ISO14000 not being prevalent enough to the general public. Hence, the company's reputation had increased by little or not increased at all. In addition, $38 \%$ companies agreed and 25\% companies strongly agreed (mean 3.686) that their company's reputation had increased after the implementation of ISO14000. The reputation increase can build up an environmental friendly image (Pouliot, 1996) of companies. Hence it may help companies to publicize to the public that this company pays more attention to the environmental impact and puts more effort to improve it. Moreover, a god reputation can also increase its competitiveness (Robinson and Clegg, 1998).

In Q9, approximately 16\% of companies indicated that the ISO14000 standard could not help to reduce most of the waste from the production process, and $28 \%$ of companies revealed that the implementation had not greatly influenced the company in reducing waste. Eventually, different companies operate with different production processes, so the level of reduced waste would vary. In addition, SMEs do not have enough resources, which would limit a lot of improvements to the environment. In order to implement the ISO14000 standard, companies were obligated to set up objectives to meet the environmental policy (Johannson, 1993; Kirkpatrick and Pouliot, 1996). However, different companies have different objectives to meet the environmental policy, so in the end it also affects the level of reduced rate of waste. Furthermore, 33\% companies agreed and 23\% strongly agree (mean 3.617) that ISO14000 could help to reduce waste. Waste reduction could help to reduce the burden of landfill in order to improve environmental issues. Moreover, waste reduction could help to reduce the cost of avoiding paying fines (Clark, 1999) and penalties, waste storage and waste transportation.. 
In Q10, it indicates that only 16\% companies agreed and 7\% companies strongly agreed the overall company's profit had increased compared to without the implementation of ISO14000. The mean was only 2.91 which were below the normal average. In order to implement and maintain ISO14000, companies were required to increase the extra resource of their companies, such as paperwork for documentary, manpower, staff training and time for management etc. (Hillary, 2004), thus this kind of resource would decrease the overall company's profit compared to without implementation of ISO14000. Large sized companies typically have enough resources to implement ISO14000, hence most large sized companies gave a response rate of 4 . However, the small and medium size enterprises (SMEs) required increased extra resources in order to increase its profit hence most SME gave the response rate of 2-3. The response to Q10 also indicates that out of the 125 companies that had implemented ISO14000, 31\% did not see ISO14000 being an effective tool to help their company to increase profit. From the $31 \%$, the majority of this was comprised of SMEs, as indicated in the analysis.

ISO14000 is an "international passport” (Tibor and Fledman, 1996), it can assist companies to enter the international trade. However, response to Q11 indicates that only 6\% companies strongly agreed and 19\% companies agreed (mean 2.833) that ISO14000 helped to increase the sales in international market. This is because $91 \%$ companies from the survey were SMEs. Some SMEs stated that their company did not have enough resources to enter the international market. Moreover, some companies stated that the local market (Australia) would be first considered, so the normal rate 3 (44\%) would be given. Q11 also indicates that $17 \%$ companies strongly disagreed and $14 \%$ companies disagreed that the implementation of ISO14000 would increase its sales in the international market. In order to meet the environmental requirements from suppliers, implementation of ISO14000 was one of the ways to do so (Walker, 2000; Edwards, 1997). Therefore, companies with ISO14000 certifications could increase its market share to win the opportunity to work with other companies. However, in Q13, it shows only 33\% companies agreed and 4\% companies strongly agreed (mean 3.124) that its' market share had increased. This could possibly due to its late implementation of ISO14000. Moreover, because of late implementation, the function of ISO14000 for companies with primarily be maintaining its old customers instead of attracting new customers. Therefore, 20\% companies stated that ISO14000 could not help them to increase its market share and 43\% companies stated that ISO14000 had not significantly impacted its market share.

As mentioned before, the extra resources were needed in implementation of ISO14000. Hence, it needed extra cost of new employees, facilities, training and to be certified by a third party, etc. Therefore, in Q14, only 24\% companies agreed and 6\% companies strongly agreed (mean 2.918) that the overall costs had reduced. In these costs, it includes the cost of material reduced, the cost of handling the waste and the cost of management which helps to avoid paying fines, etc (Sayre, 1996). ISO14000 is an environmental standard and the implementation of it will assist companies to manage its operation/management system. Therefore, a good management system can help to improve the lead time in order to increase the efficiency in the production process. However, in Q16, it shows that only $27 \%$ companies 
agreed (mean 2.988) that the lead times could be reduced by the implementation of ISO14000. This may be due to the increased paperwork in the production process in order to increase the lead time.

In response to another Yes/No question regarding the implementation of EMS before certification to ISO14000, it was found that more than 50\% companies had the non-certified EMS before implementing ISO14000.

\subsection{Disadvantages of ISO 14000 from the Survey}

Most companies claimed that the majority of disadvantages were cost and time. For the cost, companies mentioned that to implement ISO14000, it requires to spend a huge amount of money, for example, to be certified by ISO14000, it is compulsory to pay the third party audit and invest money in training staff.. Moreover, to maintain the IS014000 system, it requires additional resources which involve internal and external auditors, facilities and manpower, the cost for surveillance audits every 6 months, and the cost for continual improvement of the company's operation. Therefore, all costs mentioned above would become a huge burden for companies, especially for SMEs.

For the time, companies stated that it required both management and employee time to do it in a proper way. For instance, the time involved in the external and internal audit, surveillance audit, extra paper work for the documentation, and continual improvement of the company's operation. Moreover, companies used their time to gather data and prepare reports, and this may distract the time available for companies to focus on real environmental issues, which affects the efficiency of the production process. In addition, for some companies with limited resources will result in increased workload for staff and hence reduced efficiency to do their normal work. Furthermore, it will also require a relatively longer time to training staff, such as the time required to change the attitude of staff with a previous knowledge.

\subsection{Reasons for Implementation and Benefits of ISO14000}

Companies indicated that ISO 14000 could be used as a tool to push the company to improve environmental performance, and increase the environmental awareness. Hence, it helped to identify and reuse waste, materials, energy and resources to maintain sustainability. Moreover, because of better management by ISO14000, companies are capable to manage environmental risks and decrease OHS risks..

In addition, the implementation of ISO14000 could prove that companies desire to be good corporate citizens, be moral and ethical in the environment. Therefore, it could ensure that the companies' operations are responsible and accountable for environmental impacts and aspects.

Furthermore, companies desired to be the leader in the industry globally to lead the market and compete for the potential customers' base. Moreover, because of customer pushing towards greener products, companies need to enhance the environmental image and reputation for marketing by ISO14000. Companies also desired to have a formalization of many existing EMS activities to recognize performance and maintain discipline of an 
effective EMS. Furthermore, companies are longing for a better quality of product and management through the implementation of ISO14000. One company stated that a supply would be stopped by the customers, if company had not been certified by ISO14000. Therefore, companies implement ISO14000 to conform to customers' requirement and expectation. Besides the pressures from customers, companies are also required to comply with requirements from government and legislation to ensure all environmental laws are obeyed.

Companies mentioned that ISO14000 helped company to have a better consideration of the impact and attention to all aspects or impacts involved in production and process changes. Therefore, it helped companies to identify all waste streams, resulting in significant savings. Moreover, companies stated that ISO14000 helps to have huge impact in reducing waste, such as liquid hazardous waste, greenhouse gas, dust and fume, via the better production planning. One company indicated that because of ISO14000 implementation, the company had reduced over 500 tons of waste to landfill in three years. Furthermore, companies stated that the usage of landfill, water, electricity and gas had been reduced. Additionally, ISO14000 helped to shape the company's culture, including environmental impacts in decision making. It increased awareness of management and staff in environmental and improves workplace culture towards environment. It also helped to recycle and reuse the materials.

\section{Summary and Conclusion}

Overall, the survey revealed that the performance of ISO14000 in business aspects was not so pleasant. From the survey, it showed that most companies only agreed that ISO14000 have a significant improvement towards its reputation, outcome, and help to continue investigating new procedures and meeting customer expectation. However, ISO14000 cannot help companies to improve quality of its products, increase its market shares, sales and overall company’s profit and reduce its overall costs.

The performance of ISO14000 in environmental aspects was remarkable. Survey results showed that most companies claimed that it helped to reduce most of its waste, reduce usage of landfill and energy, such as water, gas and electricity, reduce the hazardous waste production, identify and minimize potential risks to environmental and employees, increase awareness of staff, increase the recycling and reuse of materials, and help continuous quality and environmental improvements.

In regards to the disadvantages of ISO14000, most companies stated that the cost of certification, maintenance, surveillance, training staff and additional resources are expensive. ISO14000 had used up most of the employee's time, such as preparing documentation, audits and maintaining systems. Due to spending time on this kind of work, it leaves only a limited time to focus on environmental issues and result in reduced efficiency of normal work. Furthermore as mentioned before, ISO14000 cannot help to enhance sales and market share.

The comparison between manufacturing and non-manufacturing IS014000 certified companies found that ISO14000 cannot help much for non-manufacturing companies in relation to sales in the international market, reduce cost and waste. However, ISo14000 was 
more suitable for manufacturing companies, ISO14000 helped to reduce waste and cost. The comparison of non-ISO14000 certified and ISO14000 certified companies found that different kinds of manufacturing companies have different level of pressure, but not all manufacturing companies suffer under pressure. Moreover, both non-ISO14000 and ISO14000 certified companies had mentioned that the cost of implementing ISO14000 is expensive and it is one of the impediments in the certification to ISO14000.

Finally, comparing the literature review and the data from survey had revealed that most advantages and disadvantages were similar. Nevertheless, there are still a few points of difference between literature reviews and the data from surveys, such as the enhanced quality of products after implementation of ISO14000 and pressures from customers and suppliers. ISO14000 can help to reduce the cost of material, operating and environmental management and market share had increased after implementing ISO14000.

\section{Recommendations}

It can be concluded that ISO14000 have an excellent performance in environmental aspects, significantly reducing waste and usage of materials and energy. Moreover, ISO14000 can also help in identifying and minimizing potential risks to the environment to employees' awareness to protect the environment, and to continuously improve the environment.

However, according to survey results and research, ISO14000 appears to have an average performance in business aspects. Although it has advantages in business performance such as increasing reputation, helps to continue investigating new procedures and meeting customers' requirement, it also has many disadvantages. The main factors are due to the cost of implementation and maintenance of the ISO14000 system, which are relatively expensive. The extra cost for resources will reduce the companies' overall profit hence not all companies achieve benefits in business aspects.

ISO14000 is suitable for companies with the purpose to protect the environment, but not for companies that only intend to enhance its business performance.

\section{Acknowledgment}

The authors wish to acknowledge that this is an amended version of a paper that was presented in a conference of CAD, CAM, Robotics and factory of the future in Pretoria, South Africa.

\section{References}

Bansal, K. P., \& Howard, E. (1997). Business and Natural Environment. Oxford: Butterworth Heinemann.

Bansal, P., \& Roth, K. (2000). Why companies go green: a model of ecological responsiveness. Academy of Management Journal, 43(4), 717-36. http://dx.doi.org/10.2307/1556363

Barla, P. (2007). ISO14001 certification and environmental performance in Quebec's pulp and paper industry. Journal of Environmental Economics and Management, 53, 291-306. 
http://dx.doi.org/10.1016/j.jeem.2006.10.004

Berry, M. A., \& Rondinelli, D. A. (1998). Proactive corporate environmental management: a new industrial revolution. Academy of Management Executive, 12, 1-13.

Boiral, O., \& Sala, J. M. (1998). Environmental management: should industry adopt ISO 14001? Business Horizons, 41(1), 57-64.

Chen, C. C. (2005). Incorporating green purchasing into the frame of ISO14000. Journal of Cleaner Production, 13(2005), 927-933. http://dx.doi.org/10.1016/j.jclepro.2004.04.005

Clark, D. (1999). What drives companies to seek ISO14000 certification? Pollution Engineering, Summer, 14-18.

Coulson, A. B. (1999). Corporate Environmental performance considerations with bank lending decisions. Eco-management and Auditing, 6(1), 1-10. http://dx.doi.org/10.1002/(SICI)1099-0925(199903)6:1<1::AID-EMA93>3.0.CO;2-M

Davis, J. (1991). Maintaining your EMS: the stages of EMS development. Environmental Quality management, 9(4), 77-85. http://dx.doi.org/10.1002/1520-6483(200022)9:4<77::AID-TQEM8>3.0.CO;2-\#

Edwards, M. (1997). Here today, green tomorrow. Supply Management, (25), 24-26.

Fineman, S., \& Clarke, K. (1996). Green stakeholders: industry interpretations and response. $\begin{array}{llll}\text { Journal of } & \text { Management } & \text { 316-30. }\end{array}$ http://dx.doi.org/10.1111/j.1467-6486.1996.tb00169.x

Heresy, K. (1998). Environmental management systems and cleaner production. Chichester, UL: Wiley.

Hillary, R. (2004). Environmental management systems and the smaller enterprise. Journal of Cleaner Production, 12, 561-569. http://dx.doi.org/10.1016/j.jclepro.2003.08.006

Holt, D. (1998). The perceived benefits of an environmental management standard. Business Process Management Journal, 4(3), 204-13. http://dx.doi.org/10.1108/14637159810224313

Johannson, L. (1993). How can a continuous improvement approach help your organsiation with EMS? Total Quality Environmental Management, 3(1), 127-133. http://dx.doi.org/10.1002/tqem.3310030114

Johnson, P. (1997). ISO14000:The Business Manager's Complete Guide to Environmental Management. Wiley, Canada.

Jump, R. A. (1995). Implementing ISO14001: Overcoming barriers to registration. Total Quality Environmental Management, 5(1), 9-14. http://dx.doi.org/10.1002/tqem.3310050103

Kirkpatrick, D., \& Pouliot, C. (1996). Environmental management, ISO14001 offer multiple rewards. Pollution Engineering, 28(6), 62-65.

Kittazaal, S., \& Sarkis, J. (2000). The relationship between ISO14001 and continuous source 
reduction programs. International Journal of Operations and Porudction Management, 20(2), 225-48. http://dx.doi.org/10.1108/01443570010304279

Macdonald, J. P. (2005). Strategic sustainable development using the ISO14001 standard. Journal of Cleaner Production, 13, 631-643. http://dx.doi.org/10.1016/j.jclepro.2003.06.001

Miller, G. T. (1996). Living in the environment: Principles, connections, and solutions. Belmont, CA: Wadsworth Publishing.

Montabon, F., Melnyk, S. A., Sroufe, R., \& Calantone, R. J. (2000). ISO14000:Assessing its perceived impact on corporate performance. The Journal of Supply Chain Management, Spring.

Polonsky, M. J. (1995). A stakeholder theory approach to designing environmental marketing strategy. Journal of Business and Industrial Marketing, 10(3), 29-46.

Pouliot, C. (1996). ISO14000: Beyond compliance to competitiveness. Manufacturing Engineering, 116(5), 51-56.

Robinson, C., \& Clegg, A. (1998). Environmental leadership and competitive advantage through environmental management system standards. Eco-management and Auditing, 5(1), 6-14. http://dx.doi.org/10.1002/(SICI)1099-0925(199803)5:1<6::AID-EMA74>3.0.CO;2-I

Rothery, B. (1995). Why ISO 14000 will catch ISO9000. Manufacturing Engineering, 115(5), 128.

Sayre, D. (1996). Inside ISO14000:The Competitive Advantage of Environmental Management. St. Lucie Press, USA.

Sroufe, R., Curkovic, S., Montabon, R., \& Melnyk, S. (2000). The new product design process and design for environment: crossing the chasm. International Journal of Operations and Production Management, 20(2), 267-291. http://dx.doi.org/10.1108/01443570010304297

Tabor, R. H., Stanwick, S. D., \& Uzumeri, M. V. (1996). Setting up environmental management Systems under ISO14001. The Journal of Corporate Accounting and Finance, (Spring), 19-33.

Tibor, T., \& Feldman, I. (1996). ISO14001: A Guide to the New Environmental Management Standards. Toronto, CA: Irwin Professional Publishing.

Walker, D. H. T. (2000). Client/customer or stakeholder focus? ISO14000 EMS as a construction industry case study. The TQM Magazine, 12(1), 18-26. http://dx.doi.org/10.1108/09544780010287221

Zucherman, A. (1997). The future of ISO14000 in the US. Iron Age New Steel, 13(7), 94. 


\section{Copyright Disclaimer}

2014, Vol. 2, No. 2

Copyright for this article is retained by the author(s), with first publication rights granted to the journal.

This is an open-access article distributed under the terms and conditions of the Creative Commons Attribution license (http://creativecommons.org/licenses/by/3.0/). 